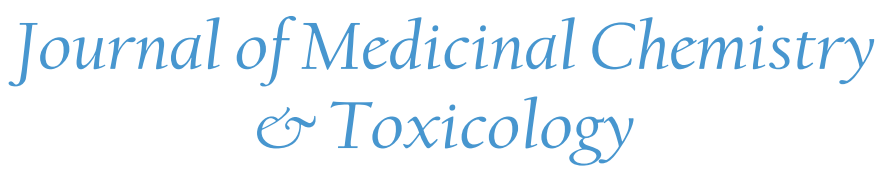

\title{
Bacterial Adherence Inhibitors for Helicobacter pylori
}

\section{Nageswara Rao Reddy Neelapu*}

Department of Biochemistry and Bioinformatics, GITAM Institute of Science, GITAM University, Rushikonda, Visakhapatnam, Andhra Pradesh, India

*Corresponding author: Nageswara Rao Reddy Neelapu, Assistant Professor, Department of Biochemistry and Bioinformatics, School of Life Sciences, GITAM Insitute of Science, GITAM University, Rushikonda, Visakhapatnam, Andhra Pradesh, India, Tel: +91-891-2840464, Mob: +91-98495 13540; +91-93937 66612, E-mail: nrneelapu@gmail.com, nrneelapu@gitam.edu

Citation: Neelapu, N.R.R. Bacterial adherence Inhibitors for Helicobacter pylori (2016) J Med Chem Tox 1(1): 1- 2.

\section{Introduction}

Human pathogen Helicobacter pylori adhere to the lining of the stomach and causes gastritis (inflammation of the stomach), duodenal or peptic ulcer, and gastric cancer (stomach cancer). Adherence of the bacteria to the mucous membrane of the gastroduodenum is the necessary initial step in the infection of the gastroduodenal tissue by the bacteria. Literature review showed that $H$. pylori uses adhesion molecules like AlpA, AlpB, BabA, HopZ, OipA and SabA to adhere to the epithelial lining of the stomach ${ }^{[1-4]}$. Reports showed that a class of sulfated glycolipids act as receptors for adherence of $H$. pylori ${ }^{[5-11]}$.

Slomiany et al. ${ }^{[5]}$ identified and reported sulfated glyceroglucolipids and its related compounds in the lipid extract of the human gastric content. The human gastric content was from the alimentary tract. Sulfated glyceroglucolipids and its related compounds are probably involved in the attachment of the organisms to the gut mucosa ${ }^{[6]}$. Slomiany et a ${ }^{[11]}$ reported that $H$. pylori adhere to triglucosyl monoalkyl-monoacyl glycerol sulfate. Lingwood et al ${ }^{[10]}$ also reported that gastric glyceroglucolipid acts as a receptor for bacterial adherence in $H$. pylori. Thus, these studies demonstrate that sulfated glycolipids of the gastric mucosa have a role in adherence of $H$. pylori.

Medicinal chemistry can be applied to synthesize the analogues for sulfated glycolipids without changing the pharmacological properties of the compound ${ }^{[12]}$. Several groups have attempted to synthesize the analogues of sulfated glycerogluco-
Received Date: September 08, 2016

Accepted Date: September 16, 2016

Published Date: September 21, 2016

lipids $^{[13-15]}$. Gigg ${ }^{[13]}$ synthesized seminolipid [3-O-(ß-D-galactopyranosyl-3-sulfate)-2-O-hexadecanpyl-1-O-hexadecyl-L-glcerol] an analogue for sulfated glycerogalactolipid. Ogawa and Horisaki $^{[14]}$ synthesized 2-O-hexadecanpyl-1-O-hexadecyl-[ $\alpha$ Glc-6SO $\left.\mathrm{Sa}_{3} \mathrm{Na}(1-6)-\alpha-\mathrm{Glc}(1-6)-\alpha-G l c-(1-3)\right]$-sn-glycerol an homologue for trisaccharide sulfated glyceroglucolipid.

Randall and Leunk ${ }^{[15]}$ synthesized sulfated gylceroglucolipids with various $\mathrm{R}, \mathrm{R}^{\prime}$ groups, where $\mathrm{R}$ or $\mathrm{R}^{\prime}$ is of hydrogen or $\mathrm{C}_{1}-\mathrm{C}_{24}$ acyl or alkyl and $\mathrm{M}^{+}$is a cationic moiety. The pool of synthesized compounds were tested for adherence of $H$. pylori by two methods. First method tested the ability of $H$. pylori to adhere to the HeLa cells in the presence or absence of sulfated glyceroglycolipids. Second method tested the ability of $H$. pylo$r i$ to establish infection in the neonatal gnotobiotic piglets. The sulfated glyceroglucolipids in combination with antimicrobials/ anti ulcer medications were tested. Pharmaceutical component inhibited the adherence of $H$. pylori to the mucosal surface of the upper gastrointestinal tract. These sulfated glyceroglucolipids can be modified to improve the binding affinities so that these compounds act as a good inhibitor for adherence of $H$. $p y$ lori. Further, sulfated glyceroglucolipids can be encapsulated in nanocarrier using nanotechnology that acts as a gastrorententive delivery system for site specific delivery, slow release of drug with more half life and also bringing the stability to the compound ${ }^{[16]}$.

Copyrights: (C) 2016 Nageswara Rao Reddy, N. This is an Open access article distributed under the terms of Creative Commons Attribution 4.0 International License. 


\section{References}

[1] Petersen, A.M., Krogfelt, K.A. Helicobacter pylori : an invading microorganism ? A review. (2003) FEMS Immunol Med Microbiol 36(3): 117-126.

[2] Ilver, D., Arnqvist, A., Ogren, J., et al. T. Helicobacter pylo$r i$ adhesion binding fucosylated histo-blood group antigens revealed by retagging. (1998) Science 279(5349): 373-377.

[3] Mahdavi, J., Sondén, B., Hurtig, M., et al. T. Helicobacter pylori SabA adhesion in persistent infection and chronic inflammation. (2002) Science 297(5581): 573-578.

[4] Moodley, Y., Linz, B., Yamaoka, Y., et al. The peopling of the Pacific from a bacterial perspective. (2009) Science 323(5913): 527-530.

[5] Slomiany, B.L., Slomiany, A., Glass, G.B.J. Glycolipids of the human gastric content structure of the sulfated glyceroglucolipid. (1977) Eur J Biochem 78(1): 33-39.

[6] Slomiany, B.L., Slomiany, A. Lipids of mucus secretions of the alimentary tract. (1984)

[7] Boedeker, E.C. In Attachment of organisms to the gut mucosa. (1984) CRC Press Inc 2: 24-30.

[8] Ishizuka, I., Yamakawa, T. Glycoglycerolipids. (1985) New Comphrensive Biochemistry 10:101-197.

[9] Evans, D.G, Evans, D.J. Jr., Moulds, J.J., et al. N-acetylneuraminyllactose-binding fibrillar hemagglutinin of Campylobacter pylori: a putative colonization factor antigen. (1988) Infect Immun 56(11): 2896-2906.
[10] Evans, D.G., Evans, D.J. Jr., Graham, D.Y. Receptor-mediated adherence of Campylobacter pylori to mouse Y-1 adrenal cell monolayers. (1989) Infect Immun 57(8): 2272-2278.

[11] Lingwood, C.A., Law, H., Pellizzari, A., et al. Gastric glycerolipid as a receptor for Campylobacter pylori. (1989) Lancet 2(8657): 238-241.

[12] Slomiany, B.L., Piotrowski, J., Samanta, A., et al. Campylobacter pylori colonization factor shows specificity for lactosylceramide sulfate and GM3 ganglioside. (1989) Biochem Int 19(4): 929-936.

[13] N.R.R, Neelapu. Medicinal chemistry and drug designing. (2016) J Med Chem Tox 1(1): 1-2.

[14] Gigg, R. The allyl ether as a protecting group in carbohydrate chemistry. Part 10 . Synthesis of 3-O- $(\beta-\mathrm{D}$-galactopyranosyl3-sulphate)-2-O-hexadecanoyl-1-O-hexadecyl-L-glycerol, seminolipid'. (1979) J Chem Soc Perkin Trans 1: 712-718.

[15] Ogawa, T., Horisaki, T. Synthesis of 2-O-hexadecanoyl-1-O-hexadecyl-[alpha-Glc-6SO3 Na-(1--6)-alpha-Glc-(1-6)-alpha-Glc-(1--3)]-sn-glycerol: a proposed structure for the glyceroglucolipids of human gastric secretion and of the mucous barrier of rat-stomach antrum (1983) Carbohydr Res 123(1): C14.

[16] Randall, J.L., Leunk, R.D. Sulfated gylceroglucolipids as inhibitors for bacterial adherence. (1992)
Ommega Online Publisher

Journal of Medicinal Chemistry \& Toxicology

Short Title : J Med Chem Toxicol
E-mail: medchemtoxic@ommegaonline.org

website: www.ommegaonline.org 